\title{
Races of the Celery Pathogen Fusarium oxysporum f. sp. apii Are Polyphyletic
}

\author{
Lynn Epstein, Sukhwinder Kaur, Peter L. Chang, Noelia Carrasquilla-Garcia, Guiyun Lyu, Douglas R. Cook, \\ Krishna V. Subbarao, and Kerry O’Donnell
}

First, second, third, fourth, and sixth authors: Department of Plant Pathology, University of California, Davis, CA 95616-8680; fifth author: Agricultural University of Hebei, Baoding, Hebei, China; seventh author: Department of Plant Pathology, University of California at Davis, 1636 E. Alisal St., Salinas, CA 93905; and eighth author: U.S. Department of Agriculture-Agricultural Research Service NCAUR, 1815 N. University St., Peoria, IL 61604.

Accepted for publication 3 December 2016.

\begin{abstract}
Fusarium oxysporum species complex (FOSC) isolates were obtained from celery with symptoms of Fusarium yellows between 1993 and 2013 primarily in California. Virulence tests and a two-gene dataset from 174 isolates indicated that virulent isolates collected before 2013 were a highly clonal population of $F$. oxysporum f. sp. apii race 2. In 2013, new highly virulent clonal isolates, designated race 4 , were discovered in production fields in Camarillo, California. Long-read Illumina data were used to analyze 16 isolates: six race 2 , one of each from races 1,3 , and 4, and seven genetically diverse FOSC that were isolated from symptomatic

comprising $38 \mathrm{~kb}$ indicated that $F$. oxysporum f. sp. apii is polyphyletic; race 2 is nested within clade 3 , whereas the evolutionary origins of races 1,3 , and 4 are within clade 2 . Based on 6,898 single nucleotide polymorphisms from the core FOSC genome, race 3 and the new highly virulent race 4 are highly similar with Nei's $\mathrm{Da}=0.0019$, suggesting that $F$. oxysporum f. sp. apii race 4 evolved from race 3 . Next generation sequences were used to develop PCR primers that allow rapid diagnosis of races 2 and 4 in planta.
\end{abstract} celery but are nonpathogenic on this host. Analyses of a 10-gene dataset
Additional keywords: Apium graveolens, Fusarium yellows, phylogeny.
Celery (Apium graveolens L. var. dulce (Miller) Pers.) is a major vegetable crop within the United States, with 12,000 ha planted with a 458-million-dollar value in 2013 (USDA National Agricultural Statistics Service 2014). Approximately $95 \%$ of celery production in the United States occurs in California and Michigan. Historically, Fusarium yellows caused by F. oxysporum f. sp. apii has been the most important disease in celery production (Correll et al. 1986a).

Fusarium yellows was first reported on the self-blanching celery cultivar Golden Self Blanching in 1914 in Michigan where it was responsible for severe outbreaks (Nelson et al. 1937). F. oxysporum f. sp. apii race 1 apparently spread on infected or infested seed or seedlings to other Midwestern states, the eastern United States, and eventually to California where it was first reported as a serious problem near Lodi in the Central Valley in 1936 (Nelson et al. 1937). F. oxysporum f. sp. apii race 1 was managed with $F$. oxysporum f. sp. apii-resistant cultivars, particularly green cultivars, such as Tall Utah 52-70, first introduced in 1952. Few reports of Fusarium yellows on celery between 1952 and 1976 are available. However, in 1976 a race 2 of $F$. oxysporum f. sp. apii was first identified in California as being virulent on Tall Utah 52-70 and Golden Self Blanching (Hart and Endo 1978; Otto et al. 1976). Since then, F. oxysporum f. sp. apii race 2 has been a production threat in California and in the other areas where it has been identified: Michigan in 1982 (Toth and Lacy 1991), New York in 1984 (Awuah et al. 1986), Texas in 1987 (Martyn et al. 1987), and Ontario, Canada in 1989 (Cerkauskas and McDonald 1989). In 1984, Puhalla (1984) reported that there were two F. oxysporum f. sp. apii races in California: race 2 and race 3, with the latter being virulent on Tall Utah cultivars but

Corresponding author: L. Epstein; E-mail address: lepstein@ucdavis.edu

*The $\boldsymbol{e}$-Xtra logo stands for "electronic extra" and indicates that one supplementary figure, three supplementary tables, and two supplementary material files are published online.

(C) 2017 The American Phytopathological Society avirulent on Golden Self Blanching. All F. oxysporum f. sp. apii race 2 isolates belong to vegetative compatibility group 0010 (Correll et al. 1986a; Puhalla 1985; Toth and Lacy 1991), which is distinct from $F$. oxysporum f. sp. apii races 1 (vegetative compatibility group [VCG] 0011 and 0012) and 3 (VCG code not designated) (Puhalla 1984), nonpathogenic isolates from celery, and other F. oxysporum formae speciales (Correll et al. 1986b; Puhalla 1985).

Following an extensive screening of celery germplasm for resistance against $F$. oxysporum f. sp. apii race 2, a major resistance gene Ful from celeriac (A. graveolens var. rapaceum PI169001) was identified (Orton et al. 1984a, b; Quiros et al. 1993). Ful and minor genes were introduced into commercial cultivars including Challenger, Stix, Sabroso, and Command. This source of resistance has been the mainstay of Fusarium yellows management for nearly three decades. In 2013, celery production in California was confronted with a new challenge with the discovery of the novel F. oxysporum f. sp. apii race 4 in Camarillo, CA. This race is highly virulent on race 2-resistant Challenger, the older cultivar Tall Utah 52-70 R Improved, and a variety of current cultivars in California.

Races are defined based on virulence on differential cultivars: race 1, virulent on Golden Self-Blanching and avirulent on Tall Utah 52-70 R Improved; race 2, virulent on Golden Self Blanching and Tall Utah 52-70 R Improved, and avirulent on Challenger; race 3 , avirulent on Golden Self Blanching and Challenger, and virulent on Tall Utah 52-70 R Improved; and race 4, virulent on Golden Self Blanching, Tall Utah 52-70 R Improved, and Challenger. The objectives of the current study were to (i) determine the diversity of F. oxysporum f. sp. apii races in California by conducting standard greenhouse virulence assays on differential celery cultivars for race evaluation; (ii) determine the phylogenetic and phylogenomic diversity of $F$. oxysporum f. sp. apii races and putatively nonpathogenic FOSC isolates recovered from celery crown and root tissues with symptoms of Fusarium yellows; and (iii) use the comparative genomic data to develop a PCR assay for the rapid detection and identification of the economically important $F$. oxysporum f. sp. apii races in planta. 


\section{MATERIALS AND METHODS}

Culture and storage conditions. Celery plants symptomatic for Fusarium yellows were collected and brought to the laboratory. Symptomatic plants with visible rotting were not sampled to avoid isolation of secondary organisms. After crown and root tissue of the symptomatic plants were washed in tap water for $2 \mathrm{~min}, 1$ to $1.5 \mathrm{~cm}$ segments of either roots or crown with symptoms consistent with Fusarium yellows were surface-disinfested with $0.62 \%$ sodium hypochlorite for $2 \mathrm{~min}$, and blotted dry; elimination of the standard post hypochlorite aqueous rinse reduced contamination without having any apparent effect on pathogen recovery. Segments that included a small discolored portion and the adjacent nondiscolored tissue were plated onto potato dextrose agar (PDA) amended with $100 \mu \mathrm{g}$ of chloramphenicol/ml. After incubation under approximately 5,000 lux cool-white fluorescent lights for 5 to 7 days at $22^{\circ} \mathrm{C}$, colonies with appearance and morphology consistent with members of the FOSC were transferred onto new PDA plates without chloramphenicol and grown for 3 to 5 days. Colonies were then hyphal-tip purified and cultures were archived. For axenic storage, $0.5 \mathrm{~cm}^{2}$ pieces of sterile filter paper were placed on PDA. After dishes were inoculated and incubated for 8 to 10 days under lights as indicated above, filter paper discs were transferred to a sterile dish, dried in a laminar flow hood for $24 \mathrm{~h}$, transferred to sterile 3-ml tubes, capped, and stored at $5^{\circ} \mathrm{C}$.

To assess whether archived isolates from celery were F. oxysporum f. sp. apii, 31 isolates from California that were primarily collected between 1993 and 1996, and six isolates from Ohio that were collected in 1996 were tested for virulence. From 2010 to 2014, we collected an additional 121, 8, 4, and 4 FOSC isolates from celery in California, Wisconsin, Michigan, and Ontario, Canada, respectively. After early results with Koch's postulates indicated that $F$. oxysporum $\mathrm{f}$. sp. apii race 2 was the cause of Fusarium yellows in California, our collections between 2010 and 2014 were biased toward the diversity of isolates emerging from the margin of symptomatic tissue. We also tested one archived $F$. oxysporum from celery (NRRL 38295, =FRC O-1120), which was deposited in 1981 by California researcher $\mathrm{S}$. N. Smith, as the "T" strain; we now refer to this strain as FoaR3.

Pathogenicity tests. Isolates were grown on PDA for 7 days under continuous fluorescent light at $22^{\circ} \mathrm{C}$ before harvesting conidia in $0.1 \%$ water agar. Before inoculation, 3 to $4 \mathrm{~cm}$ of the root tips of 8-week-old transplants were excised. Freshly cut root tips were dipped in a suspension of $10^{7}$ conidia per $\mathrm{ml}$ in $0.1 \%$ water agar for $5 \mathrm{~min}$ and then transplanted in a steam-sterilized perlite/soil (3:1) mix in planting tubes. Water agar $(0.1 \%)$ was used for a mock-inoculated control. All isolates were tested with either 8 or 10 replicates per cultivar on Tall Utah 52-70 R Improved and Challenger. All potentially nonpathogenic isolates and representatives of each race were also inoculated onto cultivar Golden Self Blanching. To establish reproducibility of results, each experimental trial included two race 2 isolates with demonstrated virulence.

After 8 weeks incubation, plants were harvested, washed, and scored for typical Fusarium yellows symptoms on a 0 to 5 severity scale: 0, asymptomatic; 1, lateral roots discolored; 2, main root discolored; 3 , crown discolored; 4, crown extensively discolored; and 5, plant dead. Based on the mock-inoculated controls, interactions between race and cultivar that were $>0.0$ and $<1.0$ were rated as nonpathogenic. To fulfill Koch's postulates, reisolations and inoculations were performed with representatives of each race.

Two-locus DNA sequences. FOSC isolates from celery are listed in Supplementary Table S1. To obtain material for a genomic DNA miniprep, 40 to $50 \mathrm{mg}$ of mycelium was scraped off the surface of 3- to 4-day-old cultures on PDA (MP Biomedicals). DNA was extracted and purified as described previously (Daugovish et al. 2012) and the concentration was determined with a NanoDrop ND-1000 spectrophotometer. An amplicon of the translation elongation factor 1- $\alpha$ (TEF1) was PCR-amplified as previously described (O'Donnell et al. 1998). Briefly, a 700-bp portion of $T E F-1 \alpha$ was amplified in a total volume of $20 \mu \mathrm{l}$ containing $1 \times$ Go Taq Green Master Mix, $0.25 \mu \mathrm{M}$ EF-1 and EF-2 primers, and 8 to $10 \mathrm{ng}$ of template DNA. PCR conditions were $94^{\circ} \mathrm{C}$ for $10 \mathrm{~min}, 40$ cycles of $94^{\circ} \mathrm{C}$ for $30 \mathrm{~s}, 52^{\circ} \mathrm{C}$ for $30 \mathrm{~s}$, and $72^{\circ} \mathrm{C}$ for $1 \mathrm{~min}$, with a final extension at $72^{\circ} \mathrm{C}$ for $10 \mathrm{~min}$. A 970-bp portion of the IGS rDNA was PCR-amplified in a total volume of $25 \mu$ l containing $1 \times$ Go Taq Green Master Mix, $0.1 \mu \mathrm{M}$ of the iNL11 (O'Donnell et al. 2009) and FoIGS-R primer (5'GCCGACACCGCGCCTCTTAA3') and 8 to $10 \mathrm{ng}$ of template DNA. PCR conditions were $94^{\circ} \mathrm{C}$ for $90 \mathrm{~s}, 35$ cycles of $94^{\circ} \mathrm{C}$ for $30 \mathrm{~s}, 57^{\circ} \mathrm{C}$ for $45 \mathrm{~s}$, and $72^{\circ} \mathrm{C}$ for $60 \mathrm{~s}$, and a final extension at $72^{\circ} \mathrm{C}$ for $10 \mathrm{~min}$.

After PCR, the amplified products were purified with an AccuPrep PCR Kit (Bioneer Corporation, Alameda, CA) and then sequenced at the Department of Biological Sciences sequencing facility at the University of California at Davis. All sequences were manually inspected for quality, aligned with either ClustalW2 or Muscle (www. ebi.ac.uk/Tools/msa/muscle/), and trimmed. All polymorphisms were checked manually. NCBI GenBank accession numbers for the 174 isolates for TEF1 are KX619056 to KX619229 and for IGS are KX619230 to KX619403.

Next generation sequencing (NGS). Sixteen FOSC isolates from celery were selected for NGS (Table 1). Total genomic DNA was purified using a protocol modified from M. Rep, University of Amsterdam. Briefly, FOSC were cultured on PDA as indicated above. Conidia from six to eight 100-mm-diameter Petri dishes were harvested in water, filtered through Miracloth to remove mycelia, washed in water, and then pelleted by centrifugation. The spore pellet was frozen, lyophilized, and ground in liquid $\mathrm{N}_{2}$ with $\leq 106-\mu$ m-diameter-glass beads (Sigma-Aldrich, St. Louis, MO). After DNA was extracted in $225 \mathrm{mM}$ sodium 4-aminosalicylate dehydrate, $22 \mathrm{mM}$ triisopropylnaphthalenesulfonic acid sodium salt, $200 \mathrm{mM}$ Tris-HCl, pH 8.0, $250 \mathrm{mM} \mathrm{NaCl}$, and $50 \mathrm{mM}$ EDTA, contaminants were removed using the phenol/chloroform/isoamyl alcohol method and a Qiagen genomic DNA (Germantown, MD) kit. Dual indexed libraries were prepared with a Nextera kit (Illumina, San Diego, CA), except for Foa_R3 and one of two preparations of 274.AC, which were prepared with a Kapa Hyper Prep kit (Kapa Biosystems, Wilmington, MA). When indicated in Table 1, libraries were whole genome-amplified for $16 \mathrm{~h}$ at $30^{\circ} \mathrm{C}$ with a REPLI-g Mini kit (Qiagen, Germantown, MD). Insert size and library quality was confirmed before sequencing using the Agilent 2100 Bioanalyzer (Agilent Technologies). DNA from the 16 strains were sequenced on an Illumina MiSeq platform as $2 \times$ $250 \mathrm{bp}$ paired end reads at the University of California at Davis Genome Center; Illumina reads from 12 additional FOSC strains sequenced by the Broad Institute were downloaded from the NCBI Short Read Archives (Ma et al. 2010, 2014). All Illumina reads were mapped to the NRRL $34936 F$. oxysporum f. sp. lycopersici 4287 (FO2) reference using BWA MEM (Li and Durbin 2010). Polymorphisms were called using the GATK pipeline (McKenna et al. 2010), which considers indel realignment and base quality score recalibration, and calls variants across all samples simultaneously through the HaplotypeCaller program. Variants were filtered using standard hard filtering parameters according to GATK Best Practices recommendations (DePristo et al. 2011; Van der Auwera et al. 2013). A total of 472,629 single nucleotide polymorphisms (SNP) were called across all 28 samples. Of these SNPs, for phylogenetic and diversity analysis, a subset of 6,898 SNPs was selected with each $\mathrm{SNP}$ at a minimum of $5 \mathrm{~kb}$ apart. The Illumina data from the 16 strains are deposited in the NCBI Short Read Archive under BioProject PRJNA318926.

Phylogenetic analyses. We first examined an aligned, 182 taxon two-locus dataset that contained partial TEF1 + IGS rDNA 
sequences (1.3 kb alignment); the study included the $174 \mathrm{FOSC}$ that we isolated from celery symptomatic for Fusarium yellows and one F. oxysporum f. sp. apii that we obtained from the ARS Culture Collection as NRRL 38295 (GenBank FJ985371.1 and FJ985604.1) that we characterized as $F$. oxysporum f. sp. apii race 3 . We also included five previously well-characterized FOSC in order to place all of the isolates within the previously defined FOSC clades 1 to 3 (NRRL 32931 from human; NRRL 34936 f. sp. lycopersici race 2; NRRL 37622, =HDV247, =NRRL54007 f. sp. pisi; NRRL 26035 (=CBS 130183) f. sp. canariensis; and NRRL 36111 (=CBS 102022) f. sp. cubense) (O'Donnell et al. 1998, 2009), and the sequences of two $F$. foetens to root the phylogeny (O'Donnell et al. 2013). Before conducting the phylogenetic analyses, the 182 taxon dataset was collapsed using Collapse ver. 1.1 (Posada 1999) to a set of 31 unique two-locus haplotypes plus a 32nd haplotype so that both f. sp. apii race 4 (11 isolates) and NRRL 38295 f. sp. apii race 3 were included in the phylogenetic analysis, even though races 3 and 4 shared the same two-locus haplotype. Maximum likelihood (ML) analyses were conducted with GARLI 1.0 (Zwickl 2006) employing the GTR $+\mathrm{I}+\Gamma$ model of evolution on the CIPRES Science Gateway TeraGrid (http://www.phylo.org); maximum parsimony (MP) analyses were implemented with PAUP* 4.0b10 (Swofford 2003), employing 10 random addition sequences per replicate, TBR branch swapping, and 1,000 pseudoreplicates of the data. ML and MP clade support was assessed by 1,000 bootstrapped pseudoreplicates of the data.

We obtained full genomic sequence data of 12 phylogenetically diverse FOSC reference strains from the Broad Institute: NRRL 34936 f. sp. lycopersici race 2; NRRL 26406 f. sp. melonis; NRRL 54003 (=MN25) f. sp. lycopersici race 3; NRRL 54002 (=Fo47) biocontrol strain from soil; NRRL 26381 (CL57) f. sp. radicis-lycopersici; NRRL 25433 f. sp. vasinfectum; NRRL 37622 (=HDV247, =NRRL54007) f. sp. pisi; NRRL 32931 from human; NRRL 54005 (=PHW815) f. sp. raphani; NRRL 54008 (=PHW808) f. sp. conglutinans race 2; NRRL 66176 (=Fo5176) from Arabidopsis; and NRRL 54006 (IL5) f. sp. cubense tropical race 4. Ten phylogenetically informative loci that were mined from the genomes of the FOSC reference strains were kindly provided by L.-J. Ma, University of Massachusetts at Amherst. Loci and their chromosomal locations in the reference genome of NRRL 34936 F. oxysporum $\mathrm{f}$. sp. lycopersici race $2(=4287)$ are as follows: chromosome 1, DNAdirected RNA polymerase III subunit $R P C 2$ and $R P B 1$; chromosome 4 , minichromosome maintenance protein 3 and anaphase-promoting complex subunit 1; chromosome 5, two hypothetical proteins FOXG_1751.3 and 2073.3; chromosome 7, DNA-directed RNA polymerase II subunit RPB2; chromosome 8, hypothetical protein FOXG 3560.3; and chromosome 9, clathrin heavy chain and DNA polymerase gamma (Supplementary Table S2 provides additional details). Sequences of these 10 genes were mined from our 16 NGS strains and from the genomes of the 12 FOSC reference strains. From these data, we obtained a 10 -gene dataset totaling $38 \mathrm{~kb}$ for 28 taxa. The data were analyzed phylogenetically by MP and ML as indicated above. The Kishino-Hasegawa likelihood test was used to assess whether the 10 genes could be analyzed as a combined dataset; most parsimonious trees (MPTs) were inferred from the individual partitions and then each dataset was constrained to the topology of a MPT inferred from the 10-gene combined dataset. The Kishino-Hasegawa likelihood test also was used to assess the monophyly of the four $F$. oxysporum f. sp. apii races and to determine if any of the partitions within the 10-gene dataset were genealogically discordant.

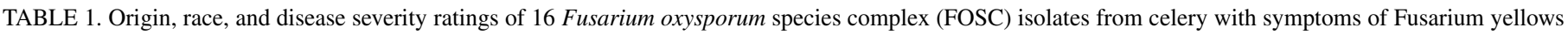
that were subjected to next generation sequencing with Illumina MiSeq

\begin{tabular}{|c|c|c|c|c|c|c|c|c|c|}
\hline \multirow[b]{3}{*}{ Sample ID } & \multirow{3}{*}{$\begin{array}{c}\text { Year } \\
\text { isolated }\end{array}$} & \multirow{3}{*}{$\begin{array}{l}\text { Collection } \\
\text { location }^{\circ}\end{array}$} & \multirow{3}{*}{$\begin{array}{l}\text { F. oxysporum } \\
\text { f. sp. apii race }\end{array}$} & \multicolumn{3}{|c|}{ Celery cultivars $^{\mathrm{n}}$} & \multirow{2}{*}{\multicolumn{3}{|c|}{ NGS analysis }} \\
\hline & & & & Tall Utah & Challenger & Golden & & & \\
\hline & & & & \multicolumn{3}{|c|}{ Disease ratings $\mathrm{p}$} & FOSC cladeq & WGA $^{r}$ & Coverage depths \\
\hline 268.2 & 2012 & Davis, CA & Race 1 & $0.1 \mathrm{~d}$ & $0.3 \mathrm{bc}$ & $1.6 \mathrm{bc}$ & 1 & WGA & 8.3 \\
\hline 003 & 1993 & Oxnard, CA & Race 2 & $2.9 \mathrm{~b}$ & $0.6 \mathrm{bc}$ & $1.2 \mathrm{~cd}$ & 3 & No & 8.6 \\
\hline $226.2 \mathrm{~A}$ & 2011 & Oxnard, CA & Race 2 & $4.1 \mathrm{a}$ & $0.4 \mathrm{bc}$ & $\mathrm{NT}^{\mathrm{t}}$ & 3 & WGA & 10.1 \\
\hline $247.1 \mathrm{~A}$ & 2011 & Oxnard, CA & Race 2 & $2.8 \mathrm{~b}$ & $0.6 \mathrm{bc}$ & $2.8 \mathrm{ab}$ & 3 & No & 10.2 \\
\hline 067 & 1994 & Santa Maria, CA & Race 2 & $3.2 \mathrm{~b}$ & $0.8 \mathrm{bc}$ & $1.5 \mathrm{bcd}$ & 3 & WGA & 8.3 \\
\hline 207.A $1 \mathrm{~A} 2^{\mathrm{u}}$ & 2010 & Santa Maria, CA & Race 2 & $3.4 \mathrm{ab}$ & $0.4 \mathrm{bc}$ & NT & 3 & WGA & 14.7 \\
\hline $258.1 \mathrm{~B}$ & 2011 & Santa Maria, CA & Race 2 & $3.2 \mathrm{~b}$ & $1.0 \mathrm{~b}$ & NT & 3 & WGA & 16.1 \\
\hline Foa_R3 ${ }^{v}$ & Before 1981 & CA (presumed) & Race 3 & $1.8 \mathrm{c}$ & $0.3 \mathrm{bc}$ & $0.8 \mathrm{~cd}$ & 2 & WGA & 26.0 \\
\hline 274.AC & 2013 & Camarillo, $\mathrm{CA}^{\mathrm{w}}$ & Race 4 & $3.0 \mathrm{~b}$ & $3.2 \mathrm{a}$ & $3.4 \mathrm{a}$ & 2 & WGA & 24.0 \\
\hline $270 . \mathrm{A}$ & 2012 & Berlin, WI & $\mathrm{NP}^{\mathrm{x}, \mathrm{y}}$ & $0.0 \mathrm{~d}$ & $0.0 \mathrm{c}$ & $0.2 \mathrm{~cd}$ & 2 & No & 11.0 \\
\hline $223.1 \mathrm{~A}$ & 2010 & Oxnard, CA & NPy & $0.1 \mathrm{~d}$ & $0.0 \mathrm{c}$ & $0.0 \mathrm{~d}$ & 3 & No & 12.2 \\
\hline $226.1 \mathrm{~A}$ & 2011 & Oxnard, CA & $\mathrm{NP}$ & $0.0 \mathrm{~d}$ & $0.0 \mathrm{c}$ & $0.0 \mathrm{~d}$ & 3 & WGA & 22.6 \\
\hline $226.1 \mathrm{~B}$ & 2011 & Oxnard, CA & NP & $0.2 \mathrm{~d}$ & $0.0 \mathrm{c}$ & $0.0 \mathrm{~d}$ & 3 & No & 11.3 \\
\hline $241.1 \mathrm{~A}$ & 2011 & Oxnard, CA & NP & $0.0 \mathrm{~d}$ & $0.2 \mathrm{bc}$ & $0.0 \mathrm{~d}$ & 3 & No & 9.7 \\
\hline 221-B & 2010 & Santa Maria, CA & NP & $0.0 \mathrm{~d}$ & $0.1 \mathrm{bc}$ & $0.5 \mathrm{~cd}$ & 3 & No & 14.1 \\
\hline $261.1 \mathrm{~A}$ & 2011 & Santa Maria, CA & NP & $0.0 \mathrm{~d}$ & $0.0 \mathrm{c}$ & $0.8 \mathrm{~cd}$ & 3 & WGA & 10.4 \\
\hline Mock & - & - & - & $0.05 \mathrm{~d}$ & $0.05 \mathrm{~d}$ & $0.2 \mathrm{~d}$ & $\mathrm{NA}^{\mathrm{z}}$ & NA & NA \\
\hline
\end{tabular}

n Tall Utah, Tall Utah 52-70 R Improved; Golden, Golden Self Blanching.

o CA, California; WI, Wisconsin.

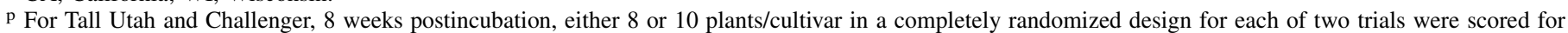
typical Fusarium yellow symptoms on a 0 to 5 severity scale: 0 , asymptomatic; 1, lateral roots discolored; 2 , main root discolored; 3 , crown discolored; 4, crown extensively discolored; and 5, plant dead. Strains were tested on Golden Self Blanching in one trial with 10 replicates, except for race 1, which was tested in two trials. Within a column, means followed by the same letter are not significantly different $(\alpha=0.05)$ according to Tukey's honest significant difference test.

q F. oxysporum species complex, based on the next generation sequence analysis shown in Table 2 and Figure 2 .

$r$ WGA, whole genome amplification.

s Estimates of coverage are based on the analysis of the 6,898 polymorphic single nucleotide polymorphisms as shown in Table 3 .

t NT, not tested.

u Equivalent IDs 207.A, 207A1A2.

$\checkmark$ Equivalent IDs Foa-R3: NRRL 38295; O-1120 = FRC O-1120.

${ }^{w}$ Camarillo, CA is adjacent to Oxnard, CA.

$x$ NP, nonpathogenic.

y Nonpathogenic, but in a two-locus haplogroup with $F$. oxysporum f. sp. apii race 1 from Michigan.

z NA, not applicable. 
F. oxysporum f. sp. apii race 2 haplogroup and race 4 PCR assays. To develop primers that differentiate between the race 2 haplogroup and race 4, Illumina sequences were assembled de novo for each of the 28 strains. Reads were filtered with Trimmomatic (Bolger et al. 2014) and assembled using Velvet (Zerbino and Birney 2008) with a kmer size of 35. Assembled sequences from all strains were combined using CAP3 (Huang and Madan 1999) to produce a common reference. All programs were run with default parameters. Illumina reads were then mapped using BWA and the reference was cut into $1 \mathrm{~kb}$ segments. The number of reads mapped in each segment was counted separately for each strain. To reduce issues associated with sequence duplication and paralogy, for each respective strain, segments were considered present only when the read count was within 2 standard deviations of the median count for that strain. Candidate segments were identified as those present in either F. oxysporum f. sp. apii race 2 or race 4 , with a 0 read count in all of the other 26 strains, and no homology in either the Fusarium Comparative Genomics Platform (FCGP, http://genomics.fusariumdb. org/intro.php) or NCBI GenBank.

Primers for PCR were designed with the Primer3Plus software (http://primer3plus.com/). We again confirmed that the selected F. oxysporum f. sp. apii race 2 haplogroup and race 4 primers were not in either FCGP or NCBI GenBank. The efficiency of candidate

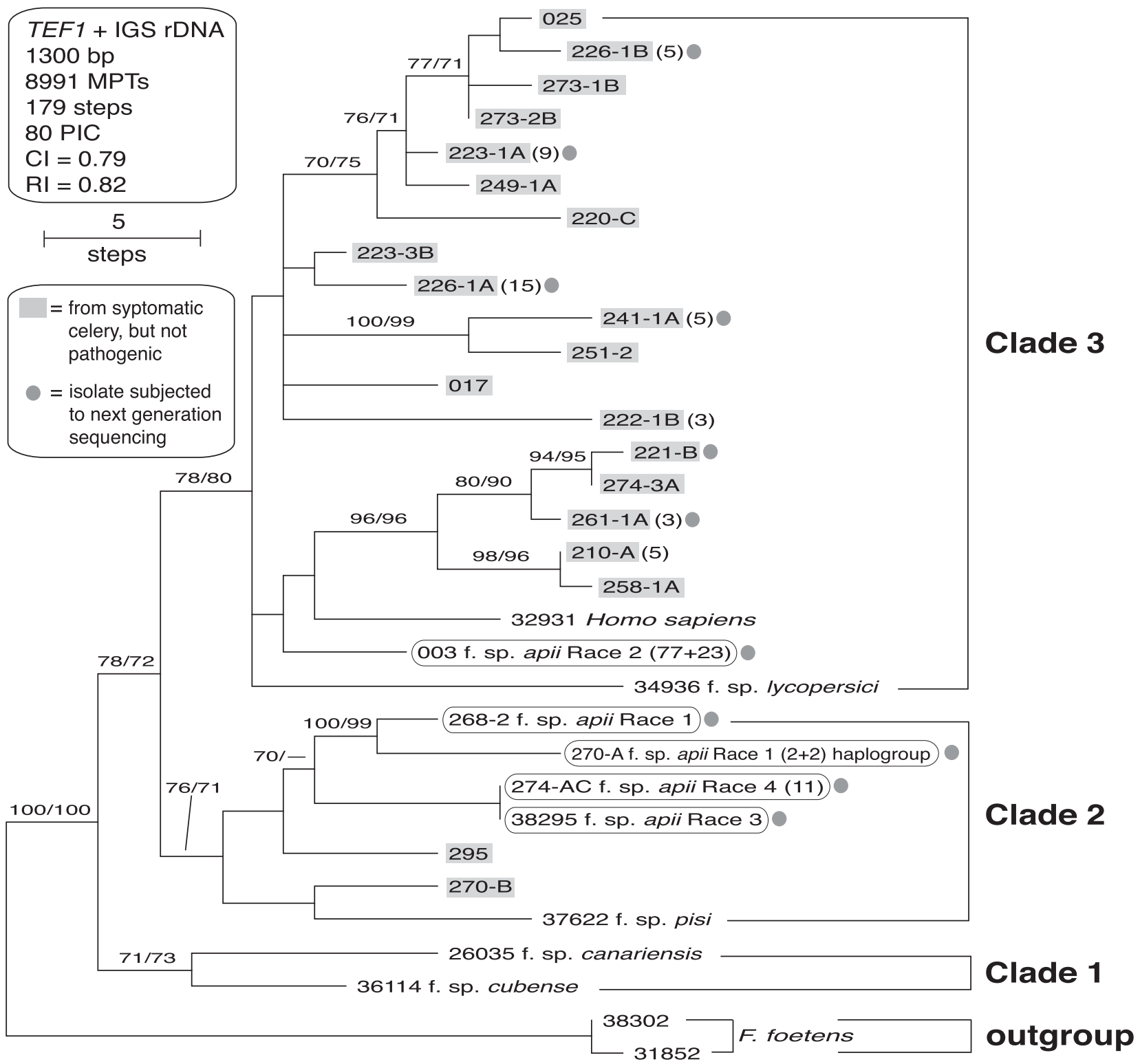

Fig. 1. Maximum parsimony phylogram inferred from portions of TEF1 and IGS rDNA totaling $1.3 \mathrm{~kb}$ from 175 Fusarium oxysporum species complex (FOSC) isolates from celery with symptoms of Fusarium yellows. Celery isolates with identical sequences were collapsed to 25 two-locus haplotypes using Collapse 1.1 (Posada 1999) to facilitate the phylogenetic analysis. Note that f. sp. apii races 3 and 4 were both included in the analysis even though they share an identical two-locus haplotype. Eleven strains that were analyzed by next generation sequencing are identified by a gray circle and described in Table 1. The number of strains in each haplogroup is indicated in parentheses; in cases in which some of the isolates were pathogenic and some were nonpathogenic, the number of isolates is shown as the number of pathogenic + the number of nonpathogenic isolates. For example, for the isolates in the haplogroup with $\mathrm{f}$. sp. apii race 2-type strains, $(77+23)$ indicates that 77 were virulent on Tall Utah $52-70 \mathrm{R}$ Improved and 23 were nonpathogenic. Similarly, in the case of the 270-A haplogroup, two of the isolates were f. sp. apii race 1 and two were nonpathogenic on the three cultivars; a third f. sp. apii race $1(268-2)$ was in another haplogroup. The tree was rooted on sequences of $F$. foetens as the outgroup. Selected non-celery isolates, identified by a five-digit NRRL strain number followed by their host, were included in the analysis to identify FOSC clades. Numbers at the nodes indicate bootstrap support based on 1,000 maximum likelihood (ML) and maximum parsimony (MP) bootstrap (BS) pseudoreplicates (i.e., ML-BS/MP-BS). The NEXUS file of the collapsed dataset is provided as Supplementary Material S1. 
TABLE 2. Summary of marker loci and tree statistics for the 10 individual partitions and combined dataset (Fig. 2)

\begin{tabular}{|c|c|c|c|c|c|c|c|c|}
\hline Gene name & Chromosome no. ${ }^{\mathrm{t}}$ & $\mathrm{bp}^{\mathrm{u}}$ & $\mathrm{MPTs}^{\mathrm{v}}$ & Tree length & $\mathrm{CI}^{\mathrm{w}}$ & $\mathrm{RI}^{\mathrm{x}}$ & $\mathrm{AUT}^{\mathrm{y}}$ & $\mathrm{PIC}^{\mathrm{z}}$ \\
\hline Hypothetical protein & 5 & 2,883 & 13 & 15 & 1 & 1 & 1 & 14 \\
\hline Hypothetical protein & 5 & 5,668 & 18 & 32 & 0.91 & 0.98 & 3 & 26 \\
\hline Hypothetical protein & 8 & 1,902 & 616 & 20 & 0.85 & 0.97 & 0 & 17 \\
\hline Minichromosome maintenance protein 3 & 4 & 2,640 & 1 & 20 & 0.95 & 0.99 & 1 & 18 \\
\hline Anaphase-promoting complex subunit 1 & 4 & 5,357 & 42 & 46 & 0.93 & 0.99 & 2 & 40 \\
\hline Clathrin heavy chain & 9 & 3,630 & 1 & 15 & 0.93 & 0.99 & 0 & 14 \\
\hline DNA directed polymerase & 9 & 3,420 & 1 & 22 & 0.91 & 0.98 & 0 & 20 \\
\hline RNA polymerase II subunit ( $R P B 2)$ & 7 & 3,813 & 17 & 31 & 0.87 & 0.97 & 4 & 23 \\
\hline RNA polymerase III subunit & 1 & 3,474 & 2 & 22 & 1 & 1 & 0 & 22 \\
\hline RNA polymerase II subunit $(R P B I)$ & 1 & 5,253 & 36 & 20 & 0.85 & 0.97 & 0 & 17 \\
\hline Combined & - & 38,060 & 18 & 295 & 0.76 & 0.94 & 11 & 211 \\
\hline
\end{tabular}

t Chromosome number is based on the whole genome sequence of NRRL 34936 (Fusarium oxysporum f. sp. lycopersici 4287) (Ma et al. 2010).

u bp, base pairs.

$\checkmark$ MPTs, most-parsimonious trees.

${ }^{\mathrm{w}} \mathrm{CI}$, consistency index, which is determined by dividing the minimum possible number of steps by those observed.

${ }^{x}$ RI, retention index.

y AUT, autapomorphy or a derived character unique to a particular taxon (i.e., not parsimony-informative).

z PIC, parsimony-informative or shared derived character.

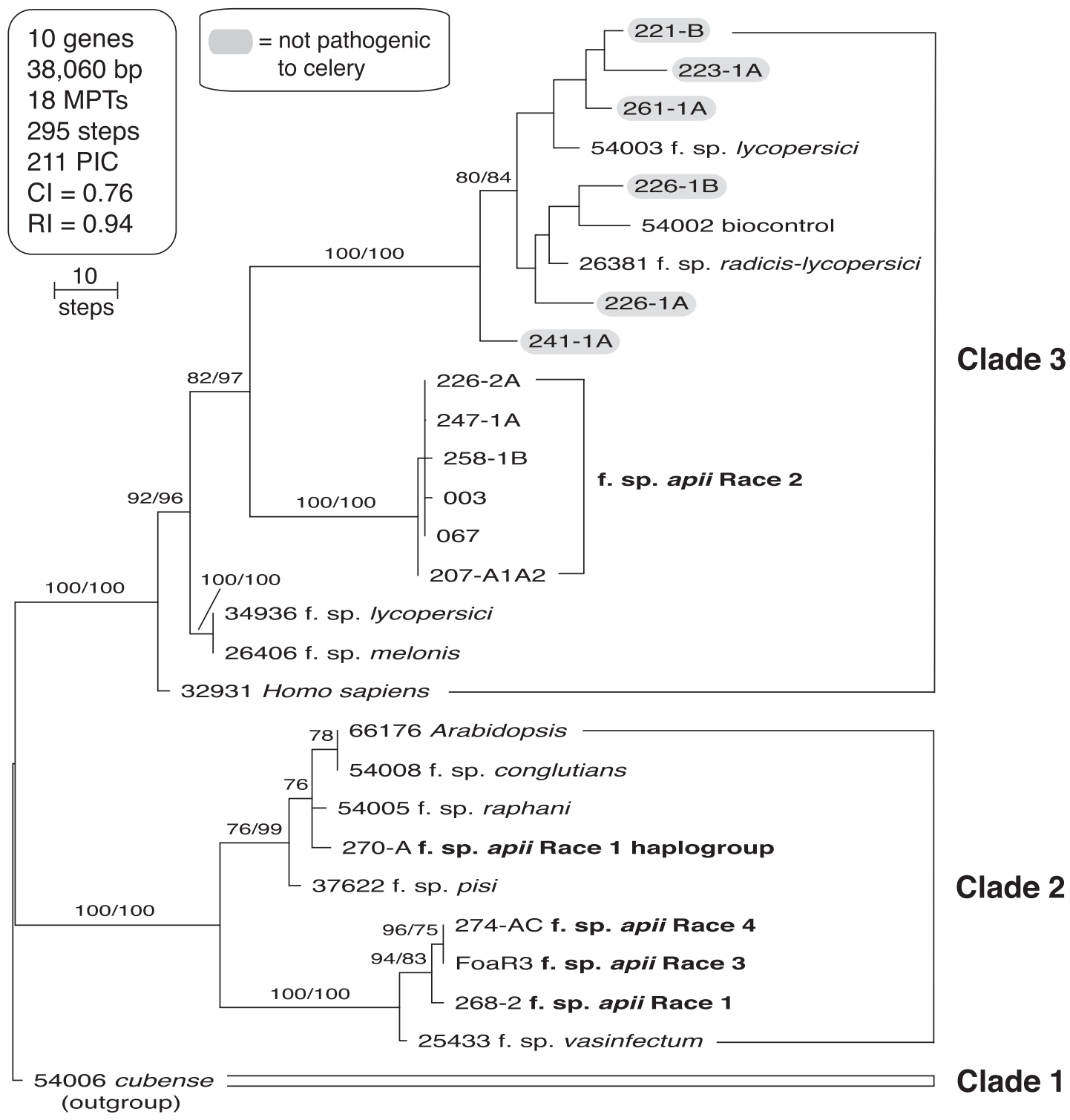

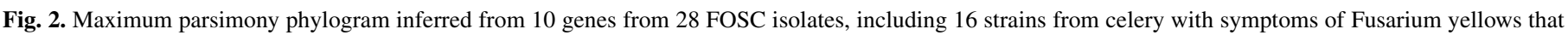

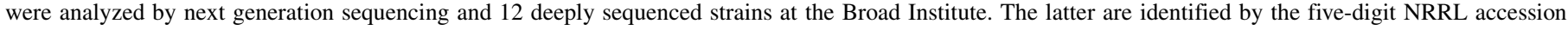

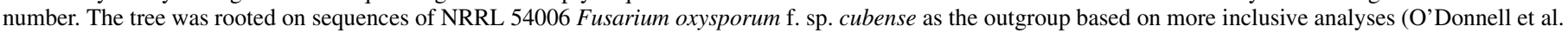

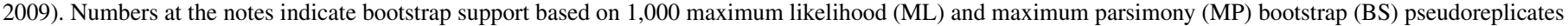
(i.e., ML-BS/MP-BS). The NEXUS file of the collapsed dataset is provided as Supplementary Material S2. 


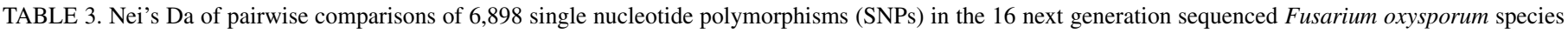
complex (FOSC) strains from symptomatic celery and the 12 FOSC reference strains at the Broad Institute ${ }^{\mathrm{w}}$

\begin{tabular}{|c|c|c|c|c|c|c|c|c|c|c|c|c|c|c|}
\hline \multirow[b]{3}{*}{ Isolate $^{z}$} & \multicolumn{14}{|c|}{ FOSC clade $3^{x}$} \\
\hline & \multirow{2}{*}{$\frac{\text { lyco }^{\mathrm{y}}}{34936}$} & \multirow{2}{*}{$\frac{\text { melo }^{\mathrm{y}}}{26406}$} & \multicolumn{6}{|c|}{ Foa race 2} & \multicolumn{6}{|c|}{ Nonpathogens (NP) in celery } \\
\hline & & & 207.A & 258.1B & $226.2 A$ & 067 & 003 & 247.1A & 226.1A & 241.1A & 223.1A & 221.B & 261.1A & 226.1B \\
\hline 34936 & 0.000 & 0.025 & 0.085 & 0.085 & 0.085 & 0.086 & 0.085 & 0.085 & 0.139 & 0.144 & 0.153 & 0.155 & 0.156 & 0.161 \\
\hline 26406 & & 0.000 & 0.088 & 0.088 & 0.089 & 0.089 & 0.089 & 0.089 & 0.143 & 0.148 & 0.157 & 0.159 & 0.160 & 0.165 \\
\hline 207.A & & & 0.000 & 0.001 & 0.001 & 0.002 & 0.001 & 0.002 & 0.093 & 0.098 & 0.104 & 0.107 & 0.110 & 0.112 \\
\hline 258.1B & & & & 0.000 & 0.001 & 0.001 & 0.002 & 0.002 & 0.092 & 0.097 & 0.103 & 0.106 & 0.109 & 0.111 \\
\hline $226.2 \mathrm{~A}$ & & & & & 0.000 & 0.002 & 0.002 & 0.002 & 0.093 & 0.097 & 0.103 & 0.107 & 0.110 & 0.112 \\
\hline 067 & & & & & & 0.000 & 0.002 & 0.002 & 0.093 & 0.098 & 0.103 & 0.107 & 0.110 & 0.113 \\
\hline 003 & & & & & & & 0.000 & 0.002 & 0.093 & 0.097 & 0.104 & 0.107 & 0.110 & 0.113 \\
\hline 247.1A & & & & & & & & 0.000 & 0.093 & 0.097 & 0.104 & 0.107 & 0.109 & 0.113 \\
\hline 226.1A & & & & & & & & & 0.000 & 0.067 & 0.053 & 0.065 & 0.070 & 0.068 \\
\hline 241.1A & & & & & & & & & & 0.000 & 0.072 & 0.077 & 0.077 & 0.080 \\
\hline 223.1A & & & & & & & & & & & 0.000 & 0.053 & 0.055 & 0.064 \\
\hline 221.B & & & & & & & & & & & & 0.000 & 0.043 & 0.061 \\
\hline 261.1A & & & & & & & & & & & & & 0.000 & 0.064 \\
\hline 226.1B & & & & & & & & & & & & & & 0.000 \\
\hline
\end{tabular}

(continued on next page)

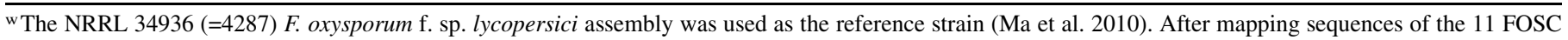
strains from the Broad Institute and our 16 FOSC strains from celery onto the reference strain, 6,898 SNPs were identified. Strains from celery are in bold type.

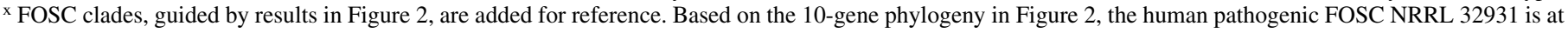
the base of clade 3; in the structure analysis here, it is within FOSC clade 2.

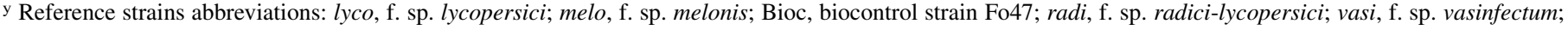
Homo, human pathogen; raph, f. sp. raphani; cong, f. sp. conglutinans; Arab, Arabidopsis-infecting; and cube, f. sp. cubensis.

${ }^{\mathrm{z}}$ FOSC reference strains are indicated by the NRRL five-digit numbers.

primers with the appropriate race-specificity was checked using real-time quantitative PCR on a 7500 Fast Real-Time PCR System (Applied Biosystems, Waltham, MA) with a dilution series of purified and Qubit-quantified $F$. oxysporum f. sp. apii DNA; efficiency was $>90 \%$. DNA was extracted from cultures or naturally infected celery crowns as described previously (Daugovish et al. 2012) except that the DNA concentration from crown tissue was determined using Qubit 2.0 (Invitrogen, Life Technologies, Carlsbad, CA). The 20- $\mu$ l PCR reaction mixture contained $1 \times$ Go Taq Green Master Mix, $200 \mathrm{nM}$ of the indicated primers, $0.2 \mu \mathrm{g}$ of BSA, and either 2 or $4 \mathrm{ng}$ of DNA from a culture, or $10 \mathrm{ng}$ of DNA from a celery crown. PCR conditions were $94^{\circ} \mathrm{C}$ for $10 \mathrm{~min}, 40$ cycles of $94^{\circ} \mathrm{C}$ for $30 \mathrm{~s}$, $60^{\circ} \mathrm{C}$ for $30 \mathrm{~s}$, and $72^{\circ} \mathrm{C}$ for $1 \mathrm{~min}$, with a final extension at $72^{\circ} \mathrm{C}$ for $10 \mathrm{~min}$.

The candidate $F$. oxysporum f. sp. apii race 2 haplogroup and race 4 primers were first tested on DNA extracts from strains that had been used to select the primers: the 16 NGS isolates; and 11 of the full genome-sequenced reference strains (NRRL 25433, 26381, 26406, 32931, 34936, 54002, 54003, 54005, 54006, 54007 , and 54008). Candidate primers were further tested on field-grown celery that was infected with either $F$. oxysporum $\mathrm{f}$. sp. apii race 2 or race 4 , the 10 additional $F$. oxysporum f. sp. apii race 4 isolates, nonpathogenic isolates from six different fields that were in the race 2 haplogroup (205C, 222-2A, 235-A, 244-2B, 251-4, and 260-1), and representatives from the haplotypes in our collection of Fusarium spp. from celery that were not included in the NGS isolates: nonpathogens 017, 210-A, 220-C, 221-B,
223-3B, 249-1A, 251-2, 258-1A, 273-1B, 273-2B, 274-3A, and 295; and race $1250-7$ from Michigan. We also tested the primers on two strains of the sister taxa of FOSC, (F. foetens NRRL 31852 and 38302) and 12 additional FOSC: two additional FOSC used in our phylogenetic analyses (NRRL 26035 and 36114), two additional FOSC f. sp. radices-lycopersici (NRRL 26379 and 26380), three additional FOSC f. sp. lycopersici (NRRL 36379, 6423, 36423 and 36425), F. oxysporum f. sp. fragariae GL1080, and four archived FOSC sp. apii (NRRL 22534, 36312, 36287, and 36316) that were reported in O'Donnell et al. (2009). Each extract was tested with three primer pairs: TEF1 as a positive control to verify that each extract had amplifiable DNA; FoaRace2 N4851, and FoaRace4 N3875. All samples tested amplified with TEF1.

\section{RESULTS}

One hundred seventy-four FOSC isolates from the crown and root tissue of celery symptomatic for Fusarium yellows were collected in Californian commercial fields from 1993 to 2014. The 174 isolates were derived from 135 plants and, based on the virulence tests, included isolates from $F$. oxysporum f. sp. apii race $1(N=3)$, F. oxysporum f. sp. apii race $2(N=77), F$. oxysporum f. sp. apii race 4 $(N=11)$ and 83 that were nonpathogenic on celery (Fig. 1). Symptomatic plants had a distinctive orangish-brown discoloration in the vasculature in the crown and/or roots, the leaves were often chlorotic and the plants were generally stunted. Virulence tests revealed that the archived isolate from celery (NRRL 38295) is 


\begin{tabular}{|c|c|c|c|c|c|c|c|c|c|c|c|c|c|}
\hline \multicolumn{13}{|c|}{ FOSC clade $2^{\mathrm{x}}$} & \multirow{2}{*}{$\frac{\text { Clade } 1^{\mathrm{x}}}{c u b e^{\mathrm{y}}}$} \\
\hline$l y c o^{\mathrm{y}}$ & $\operatorname{Bioc}^{y}$ & $r a d i^{y}$ & CA Foa race 1 & Foa race 4 & Foa race 3 & vasi ${ }^{\mathrm{y}}$ & Foa race 1 haplotype & pisi $^{\mathrm{y}}$ & Homo $^{\mathrm{y}}$ & $r a p h^{\mathrm{y}}$ & cong ${ }^{\mathrm{y}}$ & $A r a b^{\mathrm{y}}$ & \\
\hline 54003 & 54002 & 26381 & 268.2 & 274. AC & FoR3 & 25433 & 270.A & 54007 & 32931 & 54005 & 54008 & 66176 & 54006 \\
\hline 0.171 & 0.174 & 0.174 & 0.219 & 0.211 & 0.212 & 0.239 & 0.233 & 0.261 & 0.263 & 0.269 & 0.264 & 0.270 & 0.353 \\
\hline 0.175 & 0.178 & 0.178 & 0.224 & 0.215 & 0.216 & 0.243 & 0.236 & 0.264 & 0.266 & 0.272 & 0.268 & 0.275 & 0.357 \\
\hline 0.122 & 0.122 & 0.125 & 0.187 & 0.179 & 0.181 & 0.207 & 0.200 & 0.229 & 0.230 & 0.235 & 0.231 & 0.237 & 0.308 \\
\hline 0.121 & 0.122 & 0.124 & 0.187 & 0.179 & 0.181 & 0.207 & 0.200 & 0.229 & 0.231 & 0.236 & 0.231 & 0.237 & 0.307 \\
\hline 0.122 & 0.122 & 0.124 & 0.186 & 0.179 & 0.181 & 0.206 & 0.200 & 0.228 & 0.230 & 0.235 & 0.231 & 0.237 & 0.307 \\
\hline 0.122 & 0.122 & 0.125 & 0.187 & 0.180 & 0.181 & 0.207 & 0.201 & 0.229 & 0.231 & 0.236 & 0.231 & 0.237 & 0.308 \\
\hline 0.122 & 0.123 & 0.125 & 0.187 & 0.180 & 0.181 & 0.207 & 0.201 & 0.229 & 0.231 & 0.235 & 0.231 & 0.237 & 0.308 \\
\hline 0.122 & 0.122 & 0.125 & 0.186 & 0.178 & 0.180 & 0.206 & 0.200 & 0.228 & 0.230 & 0.235 & 0.230 & 0.236 & 0.307 \\
\hline 0.080 & 0.079 & 0.077 & 0.239 & 0.232 & 0.233 & 0.261 & 0.253 & 0.283 & 0.284 & 0.290 & 0.286 & 0.292 & 0.368 \\
\hline 0.086 & 0.093 & 0.092 & 0.244 & 0.236 & 0.238 & 0.266 & 0.259 & 0.288 & 0.289 & 0.296 & 0.292 & 0.297 & 0.373 \\
\hline 0.051 & 0.073 & 0.079 & 0.250 & 0.242 & 0.243 & 0.271 & 0.265 & 0.293 & 0.295 & 0.302 & 0.298 & 0.303 & 0.378 \\
\hline 0.059 & 0.077 & 0.076 & 0.254 & 0.246 & 0.248 & 0.277 & 0.268 & 0.298 & 0.300 & 0.307 & 0.302 & 0.308 & 0.386 \\
\hline 0.053 & 0.079 & 0.083 & 0.253 & 0.246 & 0.247 & 0.277 & 0.269 & 0.299 & 0.301 & 0.307 & 0.302 & 0.307 & 0.385 \\
\hline 0.066 & 0.076 & 0.059 & 0.259 & 0.252 & 0.253 & 0.282 & 0.274 & 0.306 & 0.307 & 0.313 & 0.309 & 0.314 & 0.392 \\
\hline 0.000 & 0.088 & 0.091 & 0.272 & 0.264 & 0.265 & 0.294 & 0.288 & 0.318 & 0.320 & 0.327 & 0.322 & 0.327 & 0.405 \\
\hline & 0.000 & 0.085 & 0.276 & 0.268 & 0.269 & 0.298 & 0.291 & 0.322 & 0.323 & 0.330 & 0.326 & 0.331 & 0.408 \\
\hline & & 0.000 & 0.275 & 0.267 & 0.269 & 0.298 & 0.291 & 0.322 & 0.324 & 0.330 & 0.324 & 0.330 & 0.409 \\
\hline & & & 0.000 & 0.023 & 0.023 & 0.032 & 0.125 & 0.145 & 0.147 & 0.153 & 0.150 & 0.153 & 0.351 \\
\hline & & & & 0.000 & 0.002 & 0.032 & 0.122 & 0.141 & 0.143 & 0.149 & 0.145 & 0.149 & 0.344 \\
\hline & & & & & 0.000 & 0.032 & 0.123 & 0.142 & 0.144 & 0.150 & 0.146 & 0.150 & 0.345 \\
\hline & & & & & & 0.000 & 0.141 & 0.160 & 0.162 & 0.169 & 0.166 & 0.169 & 0.376 \\
\hline & & & & & & & 0.000 & 0.072 & 0.073 & 0.083 & 0.116 & 0.118 & 0.370 \\
\hline & & & & & & & & 0.000 & 0.002 & 0.086 & 0.139 & 0.140 & 0.399 \\
\hline & & & & & & & & & 0.000 & 0.086 & 0.140 & 0.141 & 0.401 \\
\hline & & & & & & & & & & 0.000 & 0.148 & 0.150 & 0.409 \\
\hline & & & & & & & & & & & 0.000 & 0.005 & 0.411 \\
\hline & & & & & & & & & & & & 0.000 & 0.413 \\
\hline & & & & & & & & & & & & & 0.000 \\
\hline
\end{tabular}

F. oxysporum f. sp. apii race 3 (Table 1); however, isolates of this race were not recovered from symptomatic celery in this study. Instead, all of the isolates collected between 1993 and 2012 that were virulent on Tall Utah 52-70 R Improved were from race 2. During this period, three isolates that were characterized as race 1 were collected from Michigan (250-12B and 250-7) and from a celery germplasm plot in Davis, California (268-2). However, isolates forming a new F. oxysporum f. sp. apii race designated as race 4 were recovered in the Camarillo/Oxnard area, CA from 2013 onwards (Fig. 1).

A 1.3-kb TEF1 + IGS rDNA two-locus dataset for the 174 isolates and $F$. oxysporum f. sp. apii race 3 was generated. ML and MP phylogenetic analyses of the collapsed (Posada 1999), 32-taxon dataset (with 25 taxa from celery, two taxa for rooting the tree, and five reference taxa for assigning FOSC clades) revealed that F. oxysporum f. sp. apii race 2 is nested with FOSC clade 3, while F. oxysporum f. sp. apii races 1,3 , and 4 are within clade 2 . Our single archaic $F$. oxysporum f. sp. apii race 3 and the current $F$. oxysporum f. sp. apii race 4 share an identical two-locus haplotype (Fig. 1). Results of the phylogenetic analyses also indicate that among the 83 isolates scored as nonpathogenic to celery, 23 were in the race 2 haplogroup and 2 were in one of two race 1 haplogroups. The remaining 58 nonpathogenic isolates represent 20 phylogenetically diverse two-locus haplotypes, with 18 lineages nested within FOSC clade 3 and two within clade 2 (Fig. 1). Thirteen of the putatively nonpathogenic lineages were represented by singletons. By way of contrast, no allelic variation was detected within either the 100 isolates in the $F$. oxysporum $\mathrm{f}$. sp. apii race 2 haplogroup or the 11 isolates of $F$. oxysporum f. sp. apii race 4, which suggests they are clonal lineages. Lastly, it is worth noting that ML and MP bootstrap (BS) analyses of the TEF1 + IGS rDNA dataset recovered only modest support for the monophyly of FOSC clade 1 (ML-BS/MP-BS = 71/73\%), clade 2 (ML-BS/MP-BS = 76/71\%), clade 3 (ML-BS/ MP-BS $=78 / 80 \%$ ), and a sister group relationship of clades 2 and 3 (ML-BS/MP-BS $=78 / 72 \%)$.
To further elucidate evolutionary relationships of the four F. oxysporum f. sp. apii races and nonpathogens from celery, 16 strains were selected for NGS to $>8.3 \times$ coverage using a MiSeq platform (Table 1). The NRRL 34936 F. oxysporum f. sp. lycopersici race 2 (4287) strain was used as a reference genome (Ma et al. 2010 and 2014). A 10-gene dataset of phylogenetically informative genes from the 12 reference FOSC was generously provided by L.-J. Ma. After sequences from the 10 genes from the 16 celery strains were mined from their genomes, we conducted ML and MP phylogenetic analyses of the 10 genes, and the $38 \mathrm{~kb}$ combined dataset (Table 2). The 10 marker loci were mapped to six chromosomes (i.e., 1, 4, 5, 7, 8, and 9) in the core genome of NRRL 34936 (=4287) F. oxysporum f. sp. lycopersici (Ma et al. 2010). The Kishino-Hasegawa likelihood test implemented in PAUP* indicated that trees inferred from the following three partitions, when constrained to a MPT inferred from the combined dataset, were significantly different at $P<0.05$ : anaphase-promoting complex subunit 1 (from 46 to 60 steps), DNA directed polymerase (from 22 to 29 steps), and RPB2 (from 31 to 42 steps). However, when the seven-gene dataset was analyzed without these putatively discordant partitions, the topology of the MPTs and bootstrap support was essentially identical to that of the 10-gene dataset (data not shown). Thus, the MP analysis of the 10-gene dataset is presented as our strongest hypothesis of evolutionary relationships of the F. oxysporum f. sp. apii races and related FOSC (Fig. 2). In analyses of the 10-gene dataset, FOSC clades 2 and 3 were strongly supported as monophyletic (ML-BS/MP-BS $=100 / 100 \%$ ), as were $F$. oxysporum f. sp. apii races 1, 3, and 4 (ML-BS/MP-BS = 94/83\%). To assess whether F. oxysporum f. sp. apii race 2, which was nested within clade 3 , and races 1,3 , and 4 within clade 2 evolved monophyletically, the $F$. oxysporum f. sp. apii races were constrained in PAUP* to form a monophyletic group. The F. oxysporum f. sp. apii monophyly constraint was significantly worse than an unconstrained MPT inferred from the 10-gene dataset (i.e., 93 steps longer) based on 
results of the Kishino-Hasegawa likelihood test $(P<0.05)$ implemented in PAUP* (data not shown).

To further assess the genetic diversity of the selected FOSC, we mapped Illumina sequences from the 11 other FOSC reference strains and the 16 NGS strains from celery onto the assembled NRRL 34936 F. oxysporum f. sp. lycopersici reference genome. SNPs that could be scored for all isolates were selected, and a subset of 6,898 SNPs were used to quantify pairwise diversity (Table 3). Nei's Da provides a measure of SNP genetic diversity with a scale of 0 for identical isolates to 1 for isolates that are divergent at all loci. Races 3 and 4 are highly similar $(\mathrm{Da}=0.0019)$, which is within the range of the six $F$. oxysporum f. sp. apii race 2 isolates to each other. The latter vary from $0.0012 \leq \mathrm{Da} \leq 0.0020$. The California F. oxysporum f. sp. apii race 1 isolate is very similar to $F$. oxysporum f. sp. apii races 3 and 4 (average $\mathrm{Da}=0.023$ ). Of the 12 reference strains, $F$. oxysporum f. sp. apii races 1,3 , and 4 are most closely related to NRRL 25433 F. oxysporum $\mathrm{f}$. sp. vasinfectum race 7 (average $\mathrm{Da}=$ 0.032). Of the 12 reference strains, $F$. oxysporum f. sp. apii race 2 is most closely related to NRRL 34936 F. oxysporum f. sp. lycopersici race $2(\mathrm{Da}=0.085)$ and to NRRL 26406 F. oxysporum $\mathrm{f}$. sp. melonis race 1 (Ma et al. 2014) $(\mathrm{Da}=0.089)$. Assuming that the two locus haplogroups shown in Figure 1 represent clonal lineages, the six presumably nonpathogenic isolates from celery in clade 3 represent $64 \%$ of our nonpathogenic isolates; these isolates are somewhat related to $F$. oxysporum f. sp. apii race $2(0.093 \leq \mathrm{Da} \leq 0.113)$. As a group, the six nonpathogenic strains are closely related to each other $(0.053 \leq$ $\mathrm{Da} \leq 0.080)$ and to NRRL 54003 F. oxysporum $\mathrm{f}$. sp. lycopersici race 3 $(0.051 \leq \mathrm{Da} \leq 0.086)$ and to NRRL 26381 F. oxysporum f. sp. radicilycopersici $(0.0 .059 \leq \mathrm{Da} \leq 0.092)$. The six nonpathogenic strains from celery are also closely related to NRRL 54002 (=Fo47) F. oxysporum biocontrol strain $(0.051 \leq \mathrm{Da} \leq 0.086)$.

Nei's Da mirrors the clade structure. In clade $3, F$. oxysporum f. sp. apii race $2(n=6)$, the six nonpathogenic isolates from celery, and five FOSC reference strains have $0.001 \leq \mathrm{Da} \leq 0.178$. In clade 2 , F. oxysporum f. sp. apii races 1, 3, and 4, one nonpathogenic isolate from celery which is in a two-locus haplotype with two F. oxysporum f. sp. apii race 1 isolates from Michigan, and nine FOSC reference strains have $0.002 \leq \mathrm{Da} \leq 0.169$. In comparison with the single FOSC reference strain in clade 1, all of the clade 2 and 3 FOSC from celery have a $0.307 \leq \mathrm{Da} \leq 0.413$. Lastly, divergence between a clade 2 and clade 3 strain ranged from $0.180 \leq \mathrm{Da}$ to $\leq 0.327$. A structure analysis of the SNP data is shown in Supplementary Fig. S1.

We used the NGS to select PCR primers (Table 4) for rapid diagnosis of the $F$. oxysporum f. sp. apii race 2 (Fig. 3A) haplogroup and race 4 (Fig. 3B) from cultures and directly from field-infected crown tissue (Fig. 3C). As potential amplicons, we selected $1-\mathrm{kb}$ segments that appeared to be present in only F. oxysporum f. sp. apii race 2 or race 4 , and not in any of the other celery NGS, the 12 reference FOSC genomes, GenBank or FCGP. The similarity of $F$. oxysporum f. sp. apii races 3 and 4 was further indicated by the fact that we ultimately only identified one amplicon for $F$. oxysporum f. sp. apii race 4 primer design, in contrast to multiple options for $F$. oxysporum $\mathrm{f}$. $\mathrm{sp}$. apii race 2 haplogroup primers. We tested the specificity of the selected primers using 28 isolates from celery that were not in the NGS pool, including 12 nonpathogenic isolates, each of which were from a distinct haplogroup. We also tested four archived FOSC f. sp. apii that were deposited into culture collections in either 1935 or 1938, a F. oxysporum f. sp. fragariae from California,

23 diverse FOSC and two F. foetens (Supplementary Table S3). As expected, all five of the nonpathogenic isolates in the F. oxysporum f. sp. apii race 2 two-locus haplogroup amplified a single $100-$ bp product with the $F$. oxysporum f. sp. apii race 2 haplogroup primers and had no product with the race 4 primer pair. Only one of the 59 isolates that was not in the $F$. oxysporum f. sp. apii race 2 haplogroup (nonpathogenic isolate 249-1 A from celery in FOSC clade 3) produced a false positive with the F. oxysporum f. sp. apii race 2 haplogroup primer pair. All eleven F. oxysporum f. sp. apii race 4 isolates amplified a single $187 \mathrm{bp}$ product with the $F$. oxysporum f. sp. apii race 4 primer pair, and had no product with the $F$. oxysporum f. sp. apii race 2 haplogroup primer pair. In total, 2 of 59 isolates that were not F. oxysporum f. sp. apii race 4 (nonpathogenic isolates from celery 273-2B and 273-1B in FOSC clade 3) produced a false positive with a single band of approximately $190 \mathrm{bp}$ with the $F$. oxysporum $\mathrm{f}$. sp. apii race 4 primer pair. However, 15 of the 59 non-F. oxysporum $\mathrm{f}$. sp. apii race 4 isolates produced an extremely faint band of either $<100$ bp or $>1,000 \mathrm{bp}$; these would be easily distinguishable from a F. oxysporum f. sp. apii race 4 positive. Thus, there can be false positives with these primer pairs, but apparently relatively few.

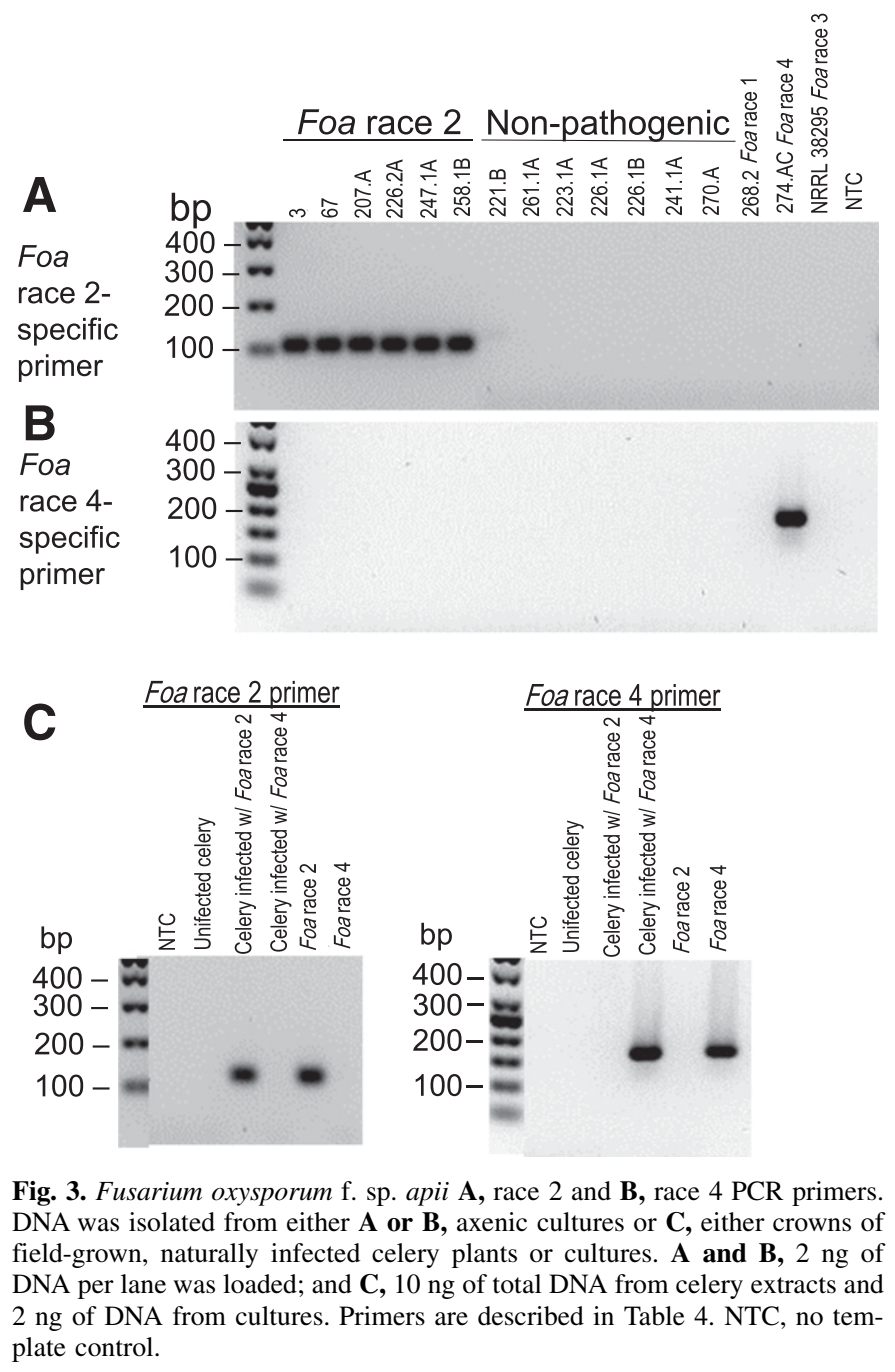

TABLE 4. Putative diagnostic PCR primers for Fusarium oxysporum f. sp. apii race 2 haplogroup and race $4^{z}$

\begin{tabular}{|c|c|c|c|c|}
\hline Specificity & Name & Forward primer $\left(5^{\prime}-3^{\prime}\right)$ & Reverse primer $\left(5^{\prime}-3^{\prime}\right)$ & Amplicon size, bp \\
\hline ce 2 & N4851 & TGTTCGAGTACATTGGAGACTTTGG & CAGCATAGATCG & 100 \\
\hline F. oxysporum f. sp. apii race 4 & $\mathrm{~N} 3875-2$ & AGGACTTGAATCACGGCTCG & CCTGCCACTCGCTTTTTGAG & 187 \\
\hline
\end{tabular}

$\mathrm{z}$ Annealing temperature, $60^{\circ} \mathrm{C}$. 


\section{DISCUSSION}

Results of the present study show that Fusarium yellows in celery in California between 1993 and 2013 was caused by F. oxysporum f. sp. apii race 2 , consistent with prior vegetative compatibility group analyses (Correll et al. 1986a; Toth and Lacy 1991). Race 2 is monomorphic, with no evidence from our next generation sequencing of a change over time or location. In addition, race 2 is genetically distinct from the 12 reference FOSC strains and to the five previously reported $F$. oxysporum f. sp. apii in O'Donnell et al. (2009); the latter FOSC strains from celery were from archived collections, with four from European collections with two isolates from Germany that were deposited by H. W. Wollenweber in 1935 (NRRL 22534, =CBS 175.35 and NRRL 36287, =CBS 176.35) and two isolates from an unidentified location that were deposited by R.R. Nelson in 1937 (NRRL 36312, =CBS 183.38 and NRRL 36316, =CBS 184.38), and NRRL 38295, which we characterized here as $F$. oxysporum f. sp. apii race 3.

F. oxysporum f. sp. apii race 4 appeared in Camarillo, CA in an intensive celery production area in 2013; as of March 2016, we confirmed it in 12 fields in Camarillo and one in neighboring Santa Paula, CA. We note that Camarillo is adjacent to Oxnard and that the Camarillo area is often called Oxnard. F. oxysporum f. sp. apii race 4 is highly virulent against all currently tested celery cultivars in California (data not shown), and has caused greater crop loss in infested fields than we have observed in F. oxysporum f. sp. apii race 2-infested fields. Consequently, it is reasonable to assume that F. oxysporum f. sp. apii race 4 has only been present in the Camarillo area for a relatively few years, since such a virulent strain would have been noticed earlier. The disease in a new field often starts as an isolated focus of infection, and we speculate that after the first plants were infected in the field where it initially appeared, the pathogen may have been moved to new fields by farm equipment or vehicles.

Although $F$. oxysporum f. sp. apii races 1, 3, and 4 are similar in sequence, they have significant differences in virulence (Table 1). Our sequence comparison of the comparatively weakly virulent $F$. oxysporum f. sp. apii race 3 with the highly virulent $F$. oxysporum f. sp. apii race 4 suggests that a relatively small change in DNA sequence may have resulted in a large change in virulence, consistent with the hypothesis by Rep and Kistler (2010) and many others (Kashiwa et al. 2016) that $F$. oxysporum isolates can evolve into new races. We note that we never isolated $F$. oxysporum f. sp. apii race 3 from field-grown celery and that our single race 3 (Foa_R3, =NRRL38295) was retrieved from an archived collection. Consequently, while it is conceivable that Foa_R3 lost virulence during storage, we also note that this isolate was collected during the time period and presumably the region where $F$. oxysporum f. sp. apii race 3 was identified (Puhalla 1984), and that the historical F. oxysporum f. sp. apii race 3 was not highly virulent, in contrast to F. oxysporum f. sp. apii race 4 . Regardless, partly because a sexual cycle has not been observed within the FOSC, the great diversity of host and cultivar specificity has been attributed to nonsexual mechanisms, especially transposon movement and chromosomal rearrangements induced by transposon recombination (Kashiwa et al. 2016; Vlaardingerbroek et al. 2016). As one example, Ma et al. (2010) presented experimental evidence that a small, transposonrich accessory chromosome with multiple virulence genes from NRRL 34936 F. oxysporum f. sp. lycopersici race 2 transformed a nonpathogenic isolate of $F$. oxysporum into a tomato pathogen by lateral transfer of an accessory chromosome.

We show here that $F$. oxysporum $\mathrm{f}$. sp. apii race 2 is in a different FOSC clade than $F$. oxysporum f. sp. apii races 1, 3, and 4. Current phylogenetic analysis supports division of the FOSC into four clades (O'Donnell et al. 2009). Together, the four FOSC clades contain hundreds of putatively clonal lineages that are plant pathogens, saprophytes, and some opportunistic pathogens of humans and other animals (Aoki et al. 2014; Laurence et al. 2014). The economically important plant pathogenic strains are the best characterized, and most are thought to have a narrow host range (Ma et al. 2013). Historically, the plant-pathogenic FOSC were categorized based on host (forma specialis, f. sp.). However, multiple formae speciales have been shown to be polyphyletic: the melon pathogen f. sp. melonis (Gordon and Martyn 1997); the banana pathogen f. sp. cubense (Fourie et al. 2009; O'Donnell et al. 1998); the cotton pathogen f. sp. vasinfectum (Skovgaard et al. 2001); and f. spp. asparagi, dianthi, gladioli, lini, and opuntiarum (Baayen et al. 2000). Here, we show that F. oxysporum f. sp. apii is another example of a polyphyletic forma specialis within the FOSC. Based on two of the FOSC reference strains, we also show that F. oxysporum f. sp. lycopersici is polyphyletic.

The NGS allowed us to develop PCR primers for diagnosis directly from crown tissue of the agronomically important races of F. oxysporum f. sp. apii from symptomatic celery (Fig. 3C); DNA isolation from symptomatic crown tissue, PCR, and gel electrophoresis can be completed in 1 day. However, although we were able to use the NGS to develop primers that only amplified DNA from either the $F$. oxysporum f. sp. apii race 2 haplogroup or race 4 and not DNA from the other NGS isolates, we had amplification from 3 of 12 nonpathogenic isolates. We note however, that assuming that our two-locus haplotypes represent clonal lineages, all three false positives were singletons in their haplotype, and consequently each only represents $0.6 \%$ of a collection that was designed to sample the diversity of FOSC isolates in symptomatic celery. In addition, we do not know the relative quantities of pathogenic and nonpathogenic isolates in the margin of symptomatic tissue. In our experience, symptomatic tissue has one $F$. oxysporum f. sp. apii race and zero to two nonpathogenic strains.

We isolated nearly equal numbers of $F$. oxysporum $\mathrm{f}$. sp. apii race $2(n=77)$ and nonpathogenic isolates $(n=83)$ that did not induce vascular discoloration in greenhouse virulence tests. However, 23 and 2 of the isolates were in the same two-locus haplotypes as F. oxysporum f. sp. apii races race 2 and 1 , respectively. Nonetheless, 58 of our 174 isolates $(33 \%)$ were from either other formae speciales of $F$. oxysporum or other saprophytic FOSC lineages. Isolation of nonpathogenic isolates from celery with Fusarium yellows has been reported previously (Correll et al. 1986b; Schneider 1984). The majority of the nonpathogenic isolates that were colocalized in symptomatic tissue are nested in FOSC clade 3. In contrast to F. oxysporum f. sp. apii races 2 and 4, the nonpathogenic isolates are phylogenetically diverse, consistent with earlier vegetative compatibility group analysis (Correll et al. 1986b). Interestingly, the subclade that includes most of our diverse nonpathogenic isolates also includes the biocontrol strain Fo47/NRRL 54002 (Alabouvette et al. 2007; Edel-Hermann et al. 2009; Fuchs et al. 1999). Data in Schneider (1984) suggest that the nonpathogenic FOSC may contribute specifically to suppression of celery Fusarium yellows. In other Fusarium diseases, nonpathogenic FOSC isolates have also been implicated as agents of suppressiveness (Bolwerk et al. 2005; Larkin et al. 1996), although other biotic agents (Mazurier et al. 2009) and abiotic factors have also been postulated. It is unknown whether the nonpathogenic isolates that share the two-locus sequence type with races 1 and 2 are either bona fide saprophytes that have lost virulence in the field (as they often do in the laboratory) or that the standard vascular-discoloration-based disease assay for Fusarium yellows has a relatively high false negative detection rate. Regardless, there is a diverse community of putatively nonpathogenic FOSC in symptomatic tissue; in preliminary greenhouse assays, we did not detect a role for these isolates in either increasing or decreasing the severity of disease (data not shown).

Although many FOSC are highly specialized plant pathogens, presumably either $F$. oxysporum f. sp. apii race 1 or 3 was considered to be a primary pathogen in both celery, which is in the Apiaceae, and in Tithonia rotundifolia in the Asteraceae (Armstrong and Armstrong 1966, 1975). Furthermore, F. oxysporum f. sp. apii has been reported to be a secondary pathogen in a broad diversity of hosts including cotton (Gossypium barbadense and G. arboretum) 
in the Malvaceae, garden pea (Pisum sativum) and sickle pod (Cassia tora) in the Fabaceae, and eggplant (Solanum melongena) in the Solanaceae (Armstrong and Armstrong 1967, 1975). Although F. oxysporum f. sp. apii races do not appear to be identical to any of the currently published races of other formae speciales based on the available molecular phylogenetic data, $F$. oxysporum f. sp. apii races 1, 3 and 4 are in FOSC clade 2, which includes strains that are pathogenic on cotton (NRRL 25433), pea (HDV247 = NRRL 37622), and other hosts.

Fusarium oxysporum f. sp. apii race 1 sensu lato appears to include a variety of strains. In his 1937 monograph, Nelson et al. (1937) concluded there were two "forms" of $F$. oxysporum f. sp. apii in Michigan and possibly a third form in California. Subsequently, Puhalla (1985) determined VCGs for isolates of $F$. oxysporum f. sp. apii race 1 from New York and France, along with one $F$. oxysporum f. sp. apii race 2 from California, and concluded that all three were in separate VCGs. These and other data led him to conclude that race 1 is polymorphic, in contrast to monomorphic race 2. In 2009, O'Donnell et al. (2009) included five relatively old isolates reported as $F$. oxysporum f. sp. apii in a two-locus sequence analysis of the FOSC; however, the race of four of them is unknown and it is unclear whether Koch's postulates were ever completed on these four isolates. Although these isolates are nested within FOSC clade 2, they are genetically distinct from our isolates. Consistent with Puhalla (1984), we never isolated $F$. oxysporum $\mathrm{f}$. sp. apii race 1 from a celery-producing region in California; we isolated $F$. oxysporum f. sp. apii race 1 (268.2) from a University of California at Davis celery germplasm plot and two F. oxysporum f. sp. apii race 1 (presumably clones) from celery in Michigan; our $F$. oxysporum f. sp. apii race 1 from California and Michigan are genetically distinct but both are in FOSC clade 2.

Nelson et al. (1937) describe the repeated planting of celery without rotation in Michigan between 1913 and his 1937 publication and the dispersal of what we now call $F$. oxysporum $\mathrm{f}$. sp. apii race 1 , at least partly by infected seedlings. Similarly, F. oxysporum f. sp. apii race 2 spread from its original focal point in California in 1976 (Otto et al. 1976) to other celery production areas (Lacy et al. 1996). Ultimately, F. oxysporum f. sp. apii race 1 and race 2 were controlled by the introduction of resistant cultivars. In contrast, fumigation (Otto et al. 1976), fungicides (Awuah et al. 1986), and rotation have not been effective in controlling Fusarium yellows. We are currently trying to identify germplasm with either resistance or tolerance to $F$. oxysporum f. sp. apii race 4. Ultimately, understanding the genetic diversity and evolutionary origins of new races will be critical for the sustainable control of Fusarium yellows.

\section{ACKNOWLEDGMENTS}

We thank the following: California Celery Research Advisory Board, USDA NIFA (CA-D-PPA-2165-H), and the Program of Study Abroad for Young Teachers by the Agricultural University of Hebei, China for funding; L.-J. Ma, University of Massachusetts at Amherst for providing unpublished results on the Fusarium reference genomes; M. Rep for his DNA purification protocol for NGS; S. Koike for collecting some of the older isolates; T. Gordon and P. Henry for the F. oxysporum f. sp. fragariae isolate; L. Pierce, D. Pereira, S. Donovan, C. Quiros, V. D'Antonio, and M. Govindarajulu Elmore for helpful conversations; and Q. Pham, R. Kim, A. Aquino, N. Villalpando, G. Doehring, and R. Nandety for assistance. The twelve assembled FOSC genomes were obtained from the Fusarium Comparative Sequencing Project, Broad Institute of Harvard and MIT (https://www.broadinstitute.org/). The raw Illumina reads from Broad Project PRJNA38293 were downloaded from NCBI. The mention of firm names or trade products does not imply that they are endorsed or recommended by the U.S. Department of Agriculture over other firms or similar products not mentioned. The USDA is an equal opportunity provider and employer.

\section{LITERATURE CITED}

Alabouvette, C., Olivain, C., L'Haridon, F., Aimé, S., and Steinberg, C. 2007. Using strains of Fusarium oxysporum to control Fusarium wilts: Dream or reality. Pages 157-177 in: Novel Biotechnologies for Biocontrol Agent
Enhancement and Management. M. Vurro and J. Gressel, eds. Springer, the Netherlands.

Aoki, T., O'Donnell, K., and Geiser, D. M. 2014. Systematics of key phytopathogenic species: Current status and future challenges. J. Gen. Plant Pathol. 80:189-201.

Armstrong, G. M., and Armstrong, J. K. 1966. Wilt of Mexican sunflower caused by the celery-wilt Fusarium. Plant Dis. Reptr. 50:391-393.

Armstrong, G. M., and Armstrong, J. K. 1967. The celery-wilt Fusarium causes wilt of garden pea. Plant Dis. Reptr. 51:888-892.

Armstrong, G. M., and Armstrong, J. K. 1975. Reflections on the wilt fusaria. Annu. Rev. Phytopathol. 13:95-103.

Awuah, R. T., Lorbeer, J. W., and Ellerbrock, L. A. 1986. Occurrence of Fusarium yellows of celery caused by Fusarium oxysporum f. sp. apii race 2 in New York and its control. Plant Dis. 70:1154-1158.

Baayen, R. P., O’Donnell, K., Waalwijk, C., Bonants, P. J. M., Cigelnik, E., Kroon, P. N. M., and Roebroeck, E. J. A. 2000. Gene genealogies and AFLP analyses within the Fusarium oxysporum complex identify monophyletic and non-monophyletic formae speciales causing wilt and rot disease. Phytopathology 90:891-900.

Bolger, A. M., Lohse, M., and Usadel, B. 2014. Trimmomatic: A flexible trimmer for Illumina sequence data. Bioinformatics 30:2114-2120.

Bolwerk, A., Lagopodi, A., Lugtenberg, B. J. J., and Bloemberg, G. V. 2005. Visualization of interactions between a pathogenic and a beneficial Fusarium strain during biocontrol of tomato foot and root rot. Mol. PlantMicrobe Interact. 18:710-721.

Cerkauskas, R. F., and McDonald, M. R. 1989. Race 2 of Fusarium oxysporum f. sp. apii new to Ontario. Plant Dis. 73:859.

Correll, J. C., Puhalla, J. E., and Schneider, R. W. 1986a. Identification of Fusarium oxysporum f. sp. apii on the basis of colony size, virulence, and vegetative compatibility. Phytopathology 76:396-400.

Correll, J. C., Puhalla, J. E., and Schneider, R. W. 1986b. Vegetative compatibility groups among nonpathogenic root-colonizing Fusarium oxysporum. Can. J. Bot. 64:2358-2361.

Daugovish, O., Bolda, M., Kaur, S., Mochizuki, M. J., Marcum, D., and Epstein, L. 2012. Drip irrigation in California strawberry nurseries to reduce the incidence of Colletotrichum acutatum in fruit production. HortScience 47: 368-373.

DePristo, M. A., Banks, E., Poplin, R., Garimella, K. V., Maguire, J. R., Hartl, C., Philippakis, A. A., Del Angel, G., Rivas, M. A., Hanna, M., and McKenna, A. 2011. A framework for variation discovery and genotyping using next-generation DNA sequencing data. Nat. Genet. 43:491-498

Edel-Hermann, V., Brenot, S., Gautheron, N., Aimé, S., Alabouvette, C., and Steinberg, C. 2009. Ecological fitness of the biocontrol agent Fusarium oxysporum Fo47 in soil and its impact on the soil microbial communities. FEMS Microbiol. Ecol. 68:37-45.

Fourie, G., Steenkamp, E. T., Gordon, T. R., and Viljoen, A. 2009. Evolutionary relationships among the Fusarium oxysporum f. sp. cubense vegetative compatibility groups. Appl. Environ. Microbiol. 75:4770-4781.

Fuchs, J. G., Moenne-Loccoz, Y., and Defago, G. 1999. Ability of nonpathogenic Fusarium oxysporum Fo47 to protect tomato against Fusarium wilt. Biol. Control 14:105-110.

Gordon, T. R., and Martyn, R. D. 1997. The evolutionary biology of Fusarium oxysporum. Annu. Rev. Phytopathol. 35:111-128.

Hart, L. P., and Endo, R. M. 1978. The reappearance of Fusarium yellows of celery in California. Plant Dis. Rep. 62:138-142.

Huang, X., and Madan, A. 1999. CAP3: A DNA sequence assembly program. Genome Res. 9:868-877.

Kashiwa, T., Suzuki, T., Sato, A., Akai, K., Teraoka, T., Komatsu, K., and Arie, T. 2016. A new biotype of Fusarium oxysporum f. sp. lycopersici race 2 emerged by a transposon-driven mutation of avirulence gene AVR1. FEMS Microbiol. Lett. 363.

Lacy, M. L., Berger, R. D., Gilbertson, R. L., and Little, E. L. 1996. Current challenges in controlling diseases of celery. Plant Dis. 80:1084-1091.

Larkin, R. P., Hopkins, D. L., and Martin, F. N. 1996. Suppression of Fusarium wilt of watermelon by nonpathogenic Fusarium oxysporum and other microorganisms recovered from disease-suppressive soil. Phytopathology 86: 812-819.

Laurence, M. H., Summerell, B. A., Burgess, L. W., and Liew, E. C. Y. 2014. Genealogical concordance phylogenetic species recognition in the Fusarium oxysporum species complex. Fungal Biol. 118:374-384.

Li, H., and Durbin, R. 2010. Fast and accurate long-read alignment with Burrows-Wheeler transform. Bioinformatics 26:589-595.

Ma, L.-J., Geiser, D. M., Proctor, R. H., Rooney, A. P., O'Donnell, K., Trail, F., Gardiner, D. M., Manners, J. M., and Kazan, K. 2013. Fusarium pathogenomics. Annu. Rev. Microbiol. 67:399-416.

Ma, L.-J., Shea, T., Young, S., Zeng, Q., and Kistler, H. C. 2014. Genome sequence of Fusarium oxysporum f. sp. melonis strain NRRL 26406, a fungus causing wilt disease on melon. Genome Announc. 2:e00730-14. 
Ma, L.-J., van der Does, H. C., Borkovich, K. A., Coleman, J. J., Daboussi, M.-J., Di Pietro, A., Dufresne, M., Freitag, M., Grabherr, M., Henrissat, B., Houterman, P. M., Kang, S., Shim, W.-B., Woloshuk, C., Xie, X., Xu, J.-R., Antoniw, J., Baker, S. E., Bluhm, B. H., Breakspear, A., Brown, D. W., Butchko, R. A. E., Chapman, S., Coulson, R., Coutinho, P. M., Danchin, E. G. J., Diener, A., Gale, L. R., Gardiner, D. M., Goff, S., Hammond-Kosack, K. E., Hilburn, K., Hua-Van, A., Jonkers, W., Kazan, K., Kodira, C. D., Koehrsen, M., Kumar, L., Lee, Y.-H., Li, L., Manners, J. M., Miranda-Saavedra, D., Mukherjee, M., Park, G., Park, J., Park, S.-Y., Proctor, R. H., Regev, A., Ruiz-Roldan, M. C., Sain, D., Sakthikumar, S., Sykes, S., Schwartz, D. C., Turgeon, B. G., Wapinski, I., Yoder, O., Young, S., Zeng, Q., Zhou, S., Galagan, J., Cuomo, C. A., Kistler, H. C., and Rep, M. 2010. Comparative genomics reveals mobile pathogenicity chromosomes in Fusarium. Nature 464:367-373.

Martyn, R. D., Barnes, L. W., and Amador, J. 1987. Fusarium yellows of celery in Texas. Plant Dis. 71:651.

Mazurier, S., Corberand, T., Lemanceau, P., and Raaijmakers, J. M. 2009. Phenazine antibiotics produced by fluorescent pseudomonads contribute to natural soil suppressiveness to Fusarium wilt. ISME J. 3:977-991.

McKenna, A., Hanna, M., Banks, E., Sivachenko, A., Cibulskis, K., Kernytsky, A., Garimella, K., Altshuler, D., Gabriel, S., Daly, M., and DePristo, M. A. 2010. The genome analysis toolkit: A MapReduce framework for analyzing next-generation DNA sequencing data. Genome Res. 20:1297-1303.

Nelson, R., Coons, G. H., and Cochran, L. C. 1937. The Fusarium yellows disease of celery (Apium graveolens L. var. dulce D.C.). Mich. Agric. Exp. Stn. Tech. Bull. 155.

O’Donnell, K., Gueidan, C., Sink, S., Johnston, P. R., Crous, P. W., Glenn, A., Riley, R., Zitomer, N. C., Colyer, P., Waalwijk, C., van der Lee, T., Moretti, A., Kang, S., Kim, H. S., Geiser, D. M., Juba, J. H., Baayen, R. P., Cromey, M. G., Bithell, S., Sutton, D. A., Skovgaard, K., Ploetz, R., Kistler, H. C., Elliott, M., Davis, M., and Sarver, B. A. 2009. A two-locus DNA sequence database for typing plant and human pathogens within the Fusarium oxysporum species complex. Fungal Genet. Biol. 46:936-948.

O’Donnell, K., Kistler, H. C., Cigelnik, E., and Ploetz, R. C. 1998. Multiple evolutionary origins of the fungus causing Panama disease of banana: Concordant evidence from nuclear and mitochondrial gene genealogies. Proc. Natl. Acad. Sci. USA 95:2044-2049.

O’Donnell, K., Rooney, A. P., Proctor, R. H., Brown, D. W., McCormick, S. P., Ward, T. J., Frandsen, R. J. N., Lysøe, E., Rehner, S. A., Aoki, T., Robert, V. A. R. G., Crous, P. W., Groenewald, J. Z., Kang, S., and Geiser, D. M. 2013. Phylogenetic analyses of $R P B 1$ and $R P B 2$ support a middle Cretaceous origin for a clade comprising all agriculturally and medically important fusaria. Fungal Genet. Biol. 52:20-31.

Orton, T. J., Durgan, M. E., and Hulbert, S. H. 1984a. Studies on the inheritance of resistance to Fusarium oxysporum f. sp. apii. Plant Dis. 68:574-578.
Orton, T. J., Hulbert, S. H., Durgan, M. E., and Quiros, C. F. 1984b. UC1, fusarium-yellows resistant celery breeding line. HortScience 19: 594.

Otto, H. W., Paulus, A. O., Snyder, M. J., Endo, R. M., Hart, L. P., and Nelson, J. 1976. A crown rot of celery. Calif. Agric. 30:10-11.

Posada, D. 1999. Collapse, Version 1.1. Department of Zoology, Brigham Young University, Salt Lake City, UT.

Puhalla, J. E. 1984. Races of Fusarium oxysporum f. sp. apii in California and their genetic interrelationships. Can. J. Bot. 62:546-550.

Puhalla, J. E. 1985. Classification of strains of Fusarium oxysporum on the basis of vegetative compatibility. Can. J. Bot. 63:179-183.

Quiros, C. F., D'Antonio, V., Greathead, A. S., and Brendler, R. 1993. UC8-1, UC10-1, and UC26-1: three celery lines resistant to Fusarium yellows. HortScience 28:351-352.

Rep, M., and Kistler, H. C. 2010. The genomic organization of plant pathogenicity in Fusarium species. Curr. Opin. Plant Biol. 13:420-426.

Schneider, R. W. 1984. Effects of non-pathogenic strains of Fusarium oxysporum on celery root infection by Fusarium oxysporum f. sp. apii and a novel use of the Lineweaver-Burk double reciprocal plot technique. Phytopathology 74:646-653.

Skovgaard, K., Nirenberg, H. I., O'Donnell, K., and Rosendahl, S. 2001. Evolution of Fusarium oxysporum f. sp. vasinfectum races inferred from multigene genealogies. Phytopathology 91:1231-1237.

Swofford, D. L. 2003. PAUP*. Phylogenetic analysis using parsimony (*and other methods), version 4. Sinauer Associates, Sunderland, MA.

Toth, K. F., and Lacy, M. L. 1991. Comparing vegetative compatibility and protein banding patterns for identification of Fusarium oxysporum f. sp. apii race 2. Can. J. Microbiol. 37:669-674.

USDA National Agricultural Statistics Service. 2014. Vegetables 2013 Summary. USDA-NASS, Washington, DC.

Van der Auwera, G. A., Carneiro, M. O., Hartl, C., Poplin, R., del Angel, G., Levy-Moonshine, A., Jordan, T., Shakir, K., Roazen, D., Thibault, J., Banks, E., Garimella, K. V., Altshuler, D., Gabriel, S. and DePristo, M. A. 2013. From FastQ data to high-confidence variant calls: The genome analysis toolkit best practices pipeline. Current Protocols in Bioinformatics. 11:11.10:11.10.1-11.10.33.

Vlaardingerbroek, I., Beerens, B., Rose, L., Fokkens, L., Cornelissen, B. J., and Rep, M. 2016. Exchange of core chromosomes and horizontal transfer of lineage-specific chromosomes in Fusarium oxysporum. Environ. Microbiol. 18:3702-3713.

Zerbino, D. R., and Birney, E. 2008. Velvet: Algorithms for de novo short read assembly using de Bruijn graphs. Genome Res. 18:821-829.

Zwickl, D. J. 2006. Genetic algorithm approaches for the phylogenetic analysis of large biological sequence datasets under the maximum likelihood criterion. Ph.D. dissert., The University of Texas, Austin. 